\title{
IMPROVING THE PROCESS PERFORMANCE OF MAGNETIC ABRASIVE FINISHING OF SS304 MATERIAL USING MULTI- OBJECTIVE ARTIFICIAL BEE COLONY ALGORITHM
}

\author{
Sandip B. Gunjal" - Padmakar J. Pawar
}

Department of Production Engineering, K. K. Wagh Institute of Engineering Education and Research, Nasik, Savitribai Phule Pune University, Pune, Maharashtra, India.

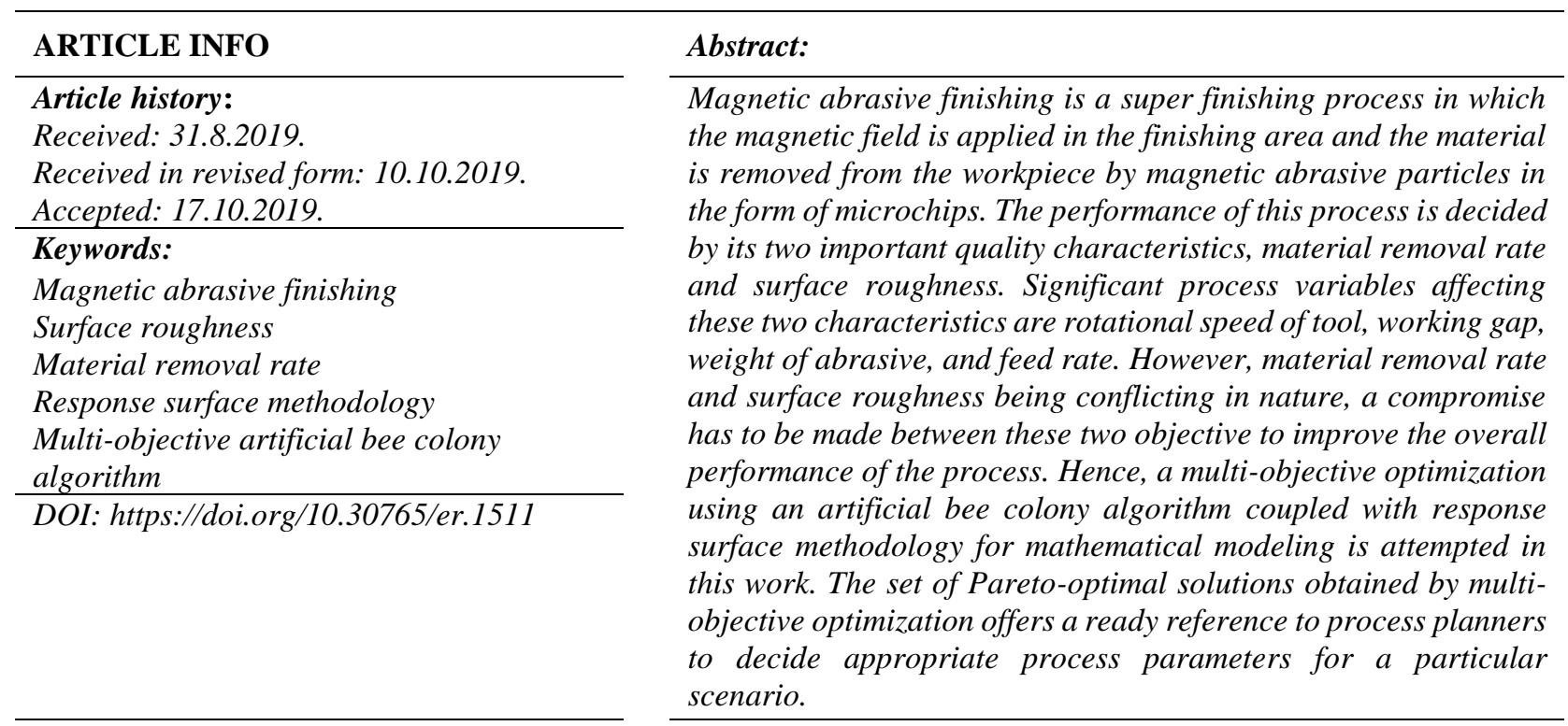

\section{Introduction}

Magnetic abrasive finishing (MAF) process is gaining attention due to its capability to obtain the better surface finish with least damage, it presents the cheap alternative for finishing as the setup can be mounted on the conventional machine tools [1-3]. MAF process is very suitable for finishing difficult to machine materials like stainless steel. Due to strength at elevated temperature, corrosion resistance, pleasing appearance, and low maintenance, stainless steel is widely used in the medical field as orthopedic implants[4] such as knee joint, hip stem, bone plates etc., for food and dairy industries as pasteurizer, homogenizer, heat exchangers, mixing tank, process tank etc. [5].In these applications, it is very essential to achieve high corrosion resistance which can be obtained by finishing these parts with very high surface finish to the grade of nanometers. However, the austenitic stainless steels are very difficult to finish by traditional finishing processes such as grinding, buffing etc. due to their high strain hardening, gumminess, high built up edge formation and low heat conductivity [6]. Although the surface finish is the main characteristic of the MAF process, it is associated with poor Material Removal Rate (MRR), which limits its practical application [7-8]. Hence, if it is possible to achieve higher MRR, MAF process can offer one of the best possible solutions to deal with this issue. Therefore, in this study, an attempt is made to increase the MRR of the process and also to obtain a better surface finish, thereby making the process more efficient.

Researchers used different processes for finishing of stainless steel such as electrochemical polishing [4], abrasive flow finishing [5] and [9], micro plasma beam irradiation [10], electron beam irradiation [11], magnetic abrasive finishing [2] and [12-16], magneto rheological abrasive flow finishing [4] and [17-24]. Thus, few researchers have applied MAF process for finishing of stainless steel material, but their study is limited to the improvement of surface finish only.

\footnotetext{
${ }^{*}$ Corresponding author

E-mail address: sbg.prod@gmail.com
} 
Researchers applied the MAF process for finishing of non-magnetic material like magnesium alloy [25-27], aluminum alloy [28, 2, 16, and 29], copper alloy [13, 27], brass [30], and titanium [31]. This process can be used for non-magnetic material as the finishing brush formed is independent of workpiece.

Attempts are also made by the investigators for optimization of magnetic abrasive finishing of different materials by considering different approaches such as Taguchi method [3], [6], [13] and [26] and [32-37], response surface methodology [13], [15] and [38-39], multi-objective particle swarm optimization [40-41], multi-objective optimization of the Ultrasonic Assisted Magnetic Abrasive Finishing [42]. It is thus observed from previous literature that the majority of the attempts are made by using single objective optimization. Only a single attempt is made so far for multi-objective optimization of MAF process using posteriori approach. Hence, there is a strong need to apply more powerful posteriori approach to verify the possibility of further improvement of MAF process. In this study, therefore an attempt is made to improve the overall performance of the MAF process with respect to its two important conflicting quality characteristics namely MRR and surface roughness by employing a newly developed multi-objective version of artificial bee colony algorithm. Parameters affecting significantly above mentioned objectives are identified as the rotational speed of tool, working gap, weight of abrasive, and feed rate. The working of the multi-objective artificial bee colony algorithm is presented in the following section.

\section{Multi-Objective Artificial Bee Colony (MO-ABC) algorithm}

Artificial Bee Colony (ABC) algorithm originated by Karaboga and Basturk (2008) is one of the successful algorithms for solving many problems related to manufacturing optimization. A multi-objective version of this algorithm (MO-ABC algorithm) proposed by Pawar et al. [43] is considered in this work. The steps in MO$\mathrm{ABC}$ algorithm is discussed below.

\section{Step 1: Selection of parameters for the algorithm}

Algorithm specific parameters in $\mathrm{MO}-\mathrm{ABC}$ required to be determined are, number of food sources (or the number of employed bees), number of scout bees, and number of on-looker bees.

\section{Step 2: Evaluate the nectar amount for every food source}

The fitness value of each solution is evaluated and is represented by its nectar amount.

\section{Step 3: Sorting of non-dominated solutions}

Every solution is checked and selected, whether it fulfills the Equation 1 in comparison to other solutions in the population

$$
\text { Obj. } 1[\mathrm{i}]<O b j .1[\mathrm{j}] \text { and Obj. } 2[\mathrm{i}]<O b j .2[\mathrm{j}], \mathrm{i} \neq \mathrm{j}
$$

The sorted solution is denoted as non-dominated, if the rules are not fulfilled for any one of the remaining solutions. Otherwise, the sorted solution is denoted as dominated. The process is repeated until all solutions are assigned non-dominated status. Those solutions assigned non-dominated status in first sorting are denoted as Rank 1 solutions, solutions assigned non-dominated status in second sorting are denoted as Rank 2 solutions and so on. Rank 1 sub-population is referred as first front set and a dummy fitness value $(f)$ is assigned to it.

\section{Step 4: For each solution normalized Euclidean distance is calculated}

The normalized Euclidean distance is calculated for each solution with respect to all other solutions using Equation 2.

$$
d_{i j}=\sqrt{\sum \frac{\left(x_{s}^{i}-x_{s}^{j}\right)}{x_{s}^{\max }-x_{s}^{\min }}}
$$

where, $x_{s}=$ value of $s^{\text {th }}$ decision variable, $i, j$ are solution numbers and $x_{s}^{\max }$ and $x_{s}^{\min }=$ upper and lower limits of the $s^{\text {th }}$ decision variable respectively. 


\section{Step 5: Calculate niche count}

A niche count $\left(n c_{i}\right)$ is a measure of crowding near a solution and it is calculated by using Equation 3 .

$$
n c_{i}=\sum \operatorname{sh}\left(d_{i j}\right)
$$

where, $\operatorname{sh}\left(d_{i j}\right)$ gives the sharing function values for all the first front solutions and it is calculated by using Equation 4.

$$
\begin{aligned}
\operatorname{sh}\left(d_{i j}\right)= & \left\{1-\left(\frac{d_{i j}}{\sigma_{\text {share }}}\right)^{2}\right\} \text { if } d_{i j}<\sigma_{\text {share }} \\
& =0 \quad \text { otherwise }
\end{aligned}
$$

where, $\sigma_{\text {share }}=$ maximum distance amongst any two solutions (to become members of a niche).

Step 6: Determine the shared fitness values

As the goal of this algorithm is to maintain the diversity, shared fitness (and not the actual fitness) is given by Equation 5 is used for further implementation. The algorithm is able to maintain diversity by appropriately lowering the value of shared fitness for a high value of niche count.

$$
\text { Shared fitness }=f / n c_{i}
$$

Step 7: Calculate probabilities of selecting food source

Now coming back to the process of ABC algorithm, the probability of selecting a particular food source by on-looker bee is evaluated based on shared fitness of that food source as given by Equation 6 .

$$
P_{i}=\frac{\sum_{k=1}^{R}\left(1 / f_{k}\right)^{-1}}{f_{i}}
$$

where, $R=$ number of food sources.

Step 8: Determining the onlooker bees

With the probability of $P_{\mathrm{i}}$, out of the total number of onlooker bees $(m)$, number of bees $(N)$ sent to a particular food source ' $i$ ' is given by Equation 7 .

$$
N=P_{i} \times m
$$

Step 9: Calculate the updated position of onlooker bee

Once the onlooker bee is allotted to the particular food source, it searches better food source in the neighborhood of assigned to it as given by Equation 8.

$$
\theta_{i}(c+1)=\theta_{i}(c) \pm \emptyset_{i}(c)
$$

where, $c=$ number of generation, $\emptyset_{i}(c)=$ randomly created step to search a food source with more nectar around ' $\theta_{i}{ }^{\prime}$. If onlooker bee allotted to the food source gets superior position, then the food source is updated. 


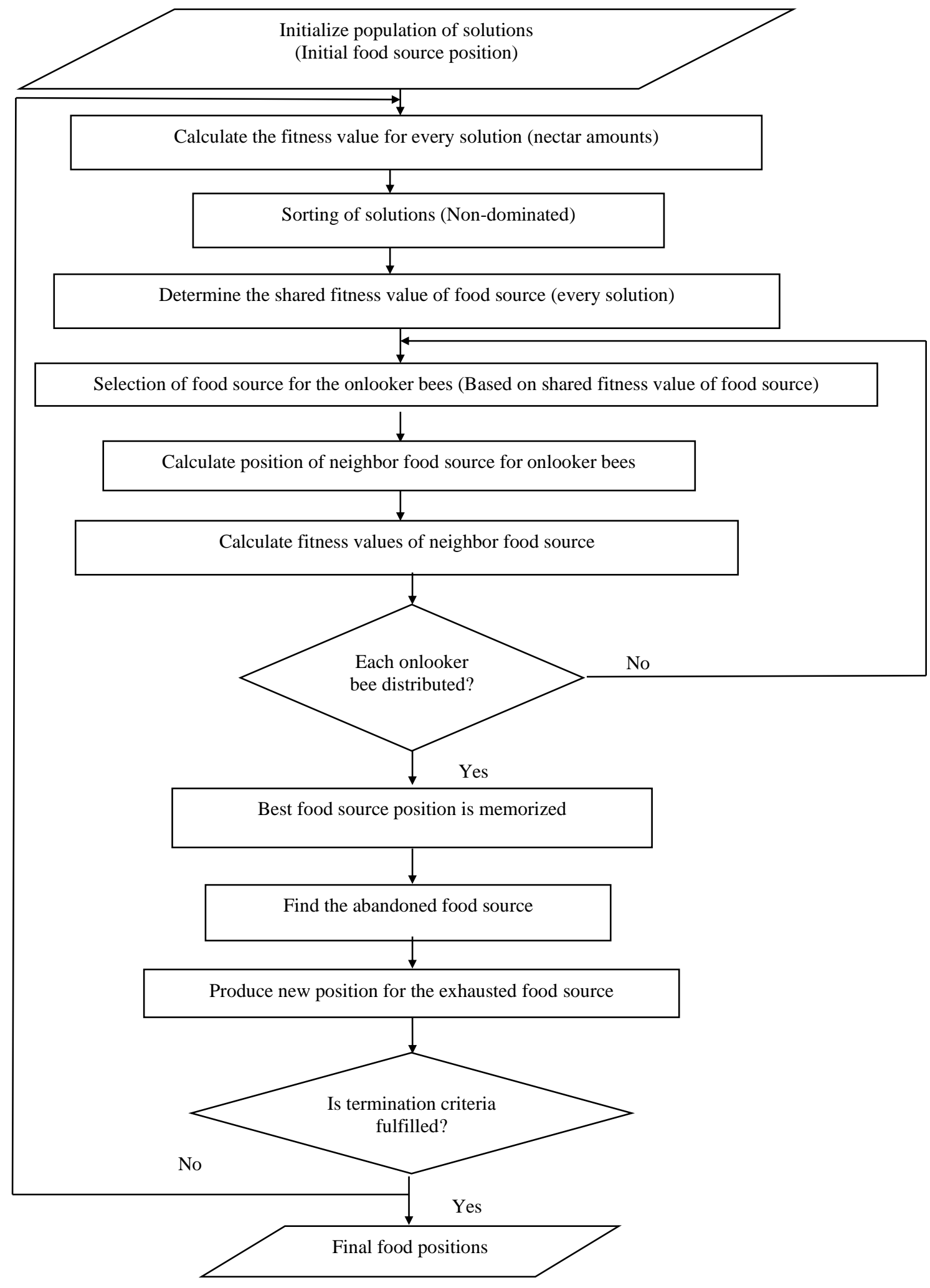

Figure 1. Flowchart of MO-ABC algorithm using the concept of non-dominated sorting [43]. 


\section{Step 10: Calculate the best solution}

For each food source, the best position is identified for the onlooker bee. For every generation, the global best of the honeybee swarm is calculated and the global best with better fitness value replaces the earlier generation global best.

\section{Step 11: Replace the scout bee}

The worst employed bees are compared with the scout solutions. The scout solution replaces the employed solution if it is better than the employed solution. Otherwise, the employed solution is moved to the next generation. A flowchart of MO-ABC is shown in Figure 1. An application example is discussed in the next section.

\section{Application Example}

Magnetic abrasive finishing of SS304 stainless steel plate of size $205 \times 130 \times 2 \mathrm{~mm}$ is considered in this work. The experimental setup is developed for finishing of flat workpieces. The tool is designed and manufactured using four sets of Neodymium boron iron (NdBFe) permanent magnets, each of size Ø $25 \times 25$ $\mathrm{mm}$. These magnets are held together with aluminum casing. Since aluminum material has low relative permeability $\left(\mu_{\mathrm{r}} \simeq 1\right)$, it do not have any effect on magnetic lines of forces. Four such magnets (each of magnetic flux density $0.6 \mathrm{~T}$ ) with north and south poles are inserted alternately in casing on pitch circle diameter of $\varnothing$ $70 \mathrm{~mm}$ as shown in Figure 2. This tool configuration will generate the magnetic lines of forces originating from the North Pole to the South Pole in a circular manner as shown in Figure 3. This complete assembly of the tool is mounted on a spindle of a vertical $\mathrm{CNC}$ machine as shown in Figure 4.

Aluminum oxide $\left(\mathrm{Al}_{2} \mathrm{O}_{3}\right)$ and silicon carbide $\left(\mathrm{S}_{i} \mathrm{C}\right)$ are commonly employed abrasives in the MAF process. However, as the finishing characteristics of $S_{i} C$ abrasive drops very swiftly due to its heavy affinity with carbon atoms, for finishing of the materials like SS304, Aluminum oxide $\left(\mathrm{Al}_{2} \mathrm{O}_{3}\right)$ is preferred. The mixture of magnetic (iron) particles and abrasive $\left(\mathrm{Al}_{2} \mathrm{O}_{3}\right)$ particles are then prepared with a certain proportion of magnetic and abrasive particles.

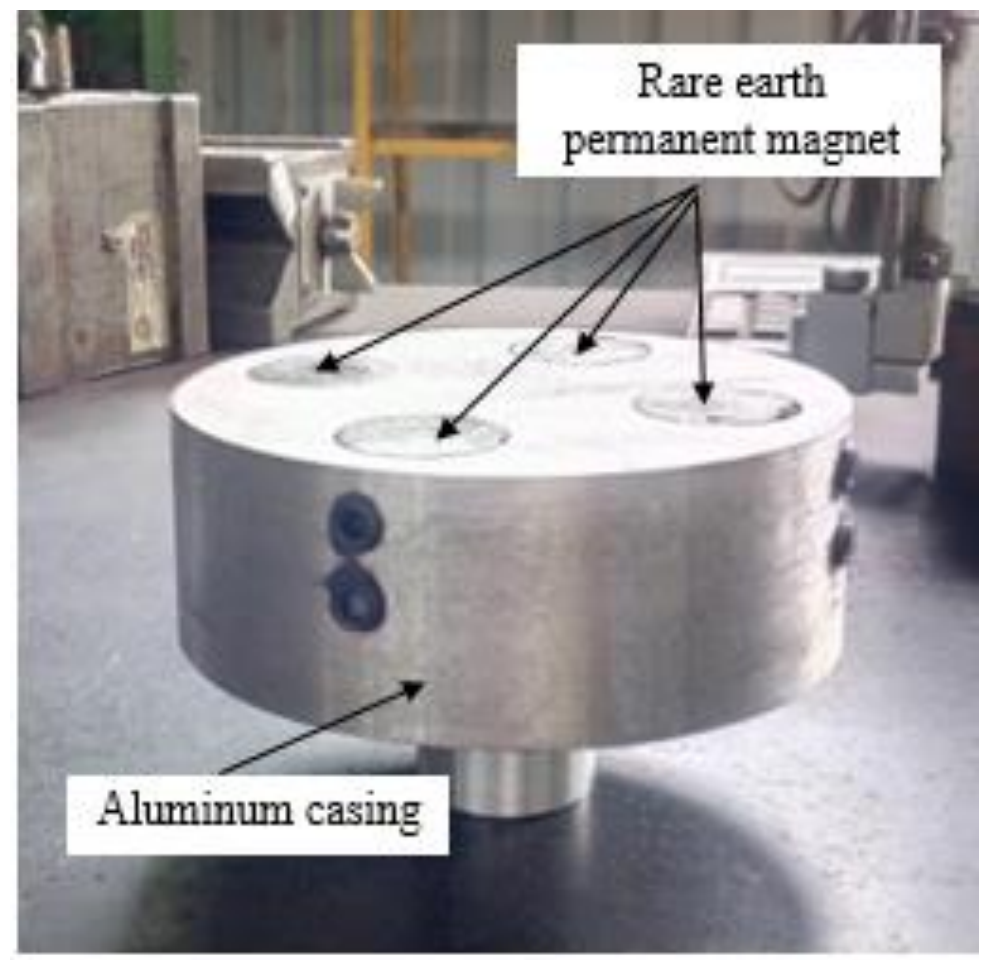

Figure 2. MAF tool with aluminum casing for holding four Neodymium boron iron (NdBFe) rare earth magnets of Ø $25 \times 25 \mathrm{~mm}$. 

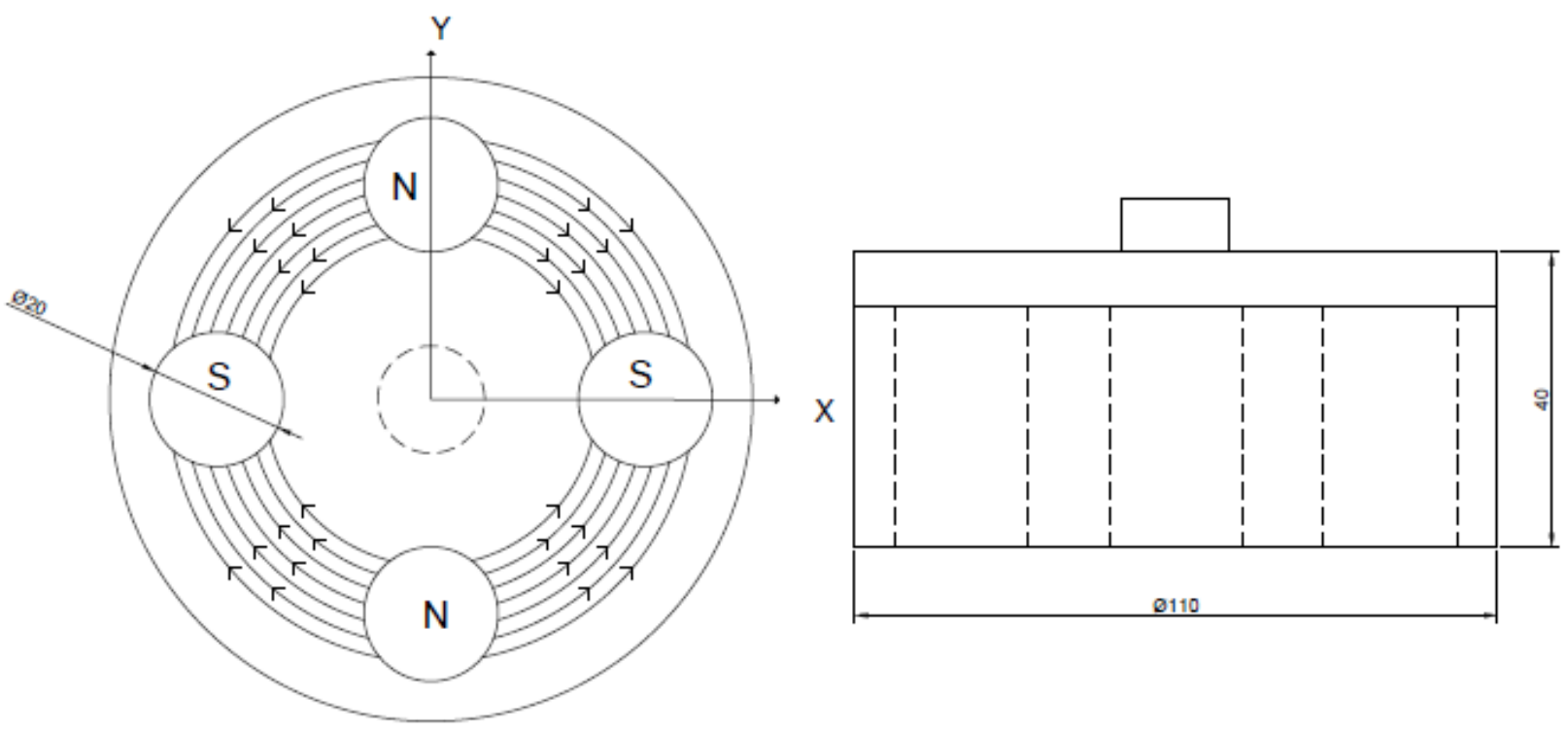

Figure 3. The schematic of poles arrangement for a permanent magnet.

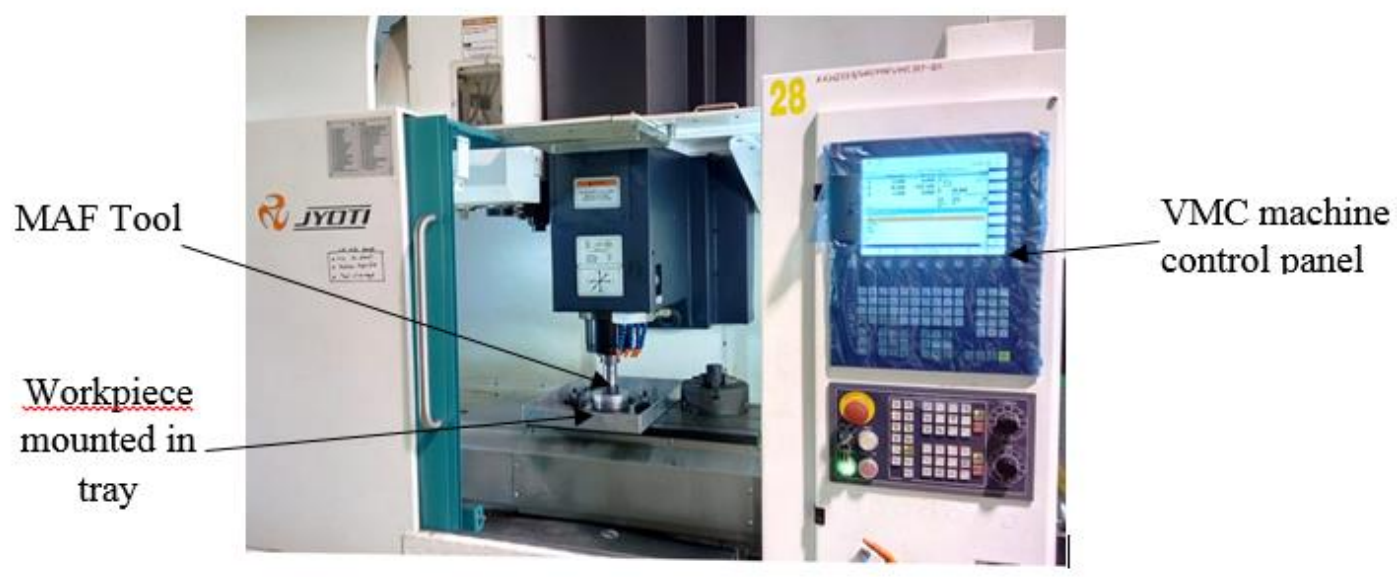

Figure 4. Experimental setup on the vertical machining center.

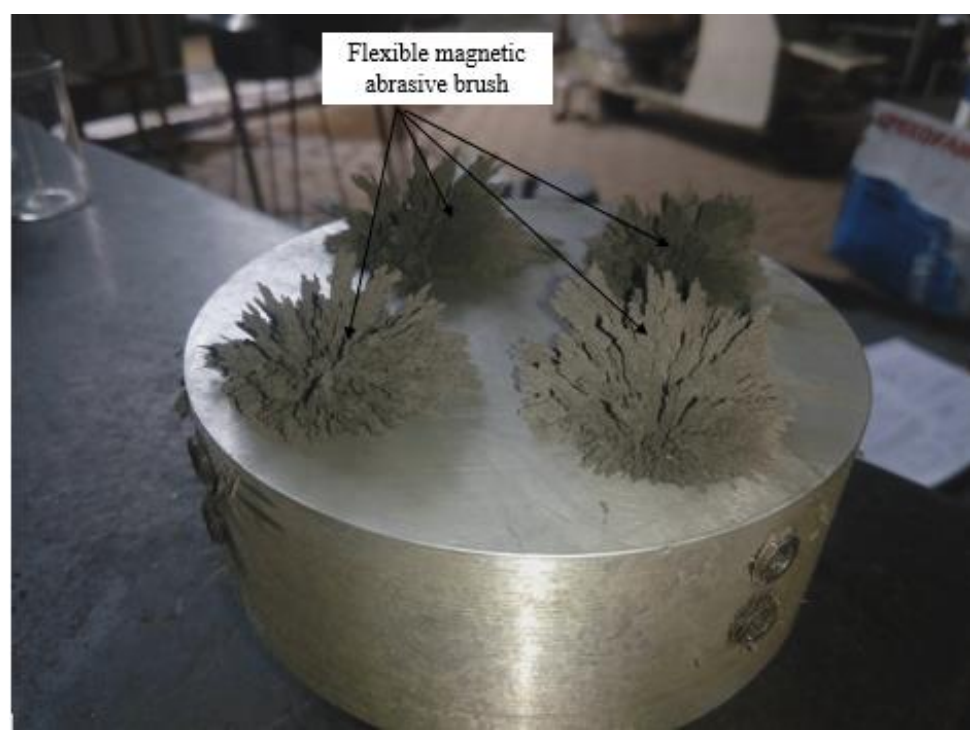

Figure 5. Formation of flexible magnetic abrasive brush. 
In this study, five such mixtures are prepared by varying the weight of abrasive particles (considering the total weight of mixture as $20 \mathrm{gm}$ ) as shown in Table 1. During the finishing process, the gap between magnetic poles and the workpiece is filled with this mixture. It is reported in the literature that the proportion of size of the iron particle to abrasive particle of 1.5 to 2 yields better surface finish [40]. Hence, in the present study iron particles of 300 mesh number and abrasive particles of 600 number are chosen.

SAE-30 lubricant is added by $5 \%$ weight of the mixture for bonding of abrasive particles and iron particles. The flexible magnetic abrasive brush is formed when this mixture makes contact with the magnetic lines, as shown in Figure 5.

The rotational speed of tool has an effect on the centripetal force, which is required to hold the mixture of abrasive and iron particles. The variation in the working gap varies the magnetic flux density which controls the normal force and finishing torque in the finishing area. The weight of abrasive in the mixture will control the strength of magnetic abrasive brush formed and the number of cutting edges available for finishing operation. Feed rate controls the total number of collisions with the peaks of the workpiece surface. Therefore, in the present work, rotational speed of the tool (rpm), working gap between workpiece and tool (mm), weight of abrasive ( $\mathrm{gm})$ and feed rate $(\mathrm{mm} / \mathrm{min})$ were selected as process parameters. At higher tool $\mathrm{rpm}$, centripetal force required to hold the Magnetic Abrasive Particles (MAP) is insufficient, and instead of indentation into the workpiece, abrasive particles may topple [44], while at very low rpm the finishing characteristics will be decreased [13]. Thus, the range for rpm of the tool was chosen from pilot experiments. Through pilot experiments, it was observed that, negligible change in surface roughness is obtained for working gap greater than $1.5 \mathrm{~mm}$, this could be due to decrease in finishing torque and normal force with an increase in working gap [44]. Therefore, the higher limit of $1.5 \mathrm{~mm}$ was chosen for the working gap. While a quick fall in the surface finish was noted for working gap below $0.5 \mathrm{~mm}$. This may be due to reduction in total number of abrasives [45]. Therefore, a minimum limit of a working gap was selected as $0.5 \mathrm{~mm}$. In general, with an increase in weight of abrasive, cutting edges available will be higher, but proportionally the finishing force on the abrasive particle reduces. The weight of abrasive is chosen based on pilot experiments. The higher feed rate would produce an ineffective surface finish on the workpiece while a lower feed rate would result in a high finishing time [13]. Thus, the feed rate was chosen based on pilot experiments in the range $5 \mathrm{~mm} / \mathrm{min}$ to $25 \mathrm{~mm} / \mathrm{min}$. Table 1 shows the various process parameters and their levels used for the study. The magnetic flux density in the working gap is calculated by using the Equation9,

$$
B^{2}=\frac{B^{\prime 2}}{2 \mu_{0}}\left(1-\frac{1}{\mu_{m}}\right)
$$

where,

$B=$ Magnetic flux density with MAP

$B$ '= Magnetic flux density without MAP

$\mu_{o}=$ Magnetic permeability of air

$\mu_{m}=$ Magnetic permeability of MAP, it is evaluated by using Equation 10,

$$
\mu_{m}=\frac{2+\mu_{f}-2\left(1-\mu_{f}\right) V_{i}}{2+\mu_{f}+\left(1-\mu_{f}\right) V_{i}}
$$

where,

$\mu_{f}=$ Magnetic permeability of iron particles

$V_{i}=$ Volumetric fraction of iron powder in working gap.

In this work, MRR and surface roughness are selected as quality characteristics. Initially, all the workpieces are ground to uniform surface roughness value of $0.430 \mu \mathrm{m}$ as shown in Figure 10. Surface roughness value is measured at three positions after proper cleaning of finished

workpiece surface with acetone and then the average is taken to get the single value which represents the final surface roughness. Surface roughness is measured using Zeiss (Surfcom130A) tester, sampling length of 0.08 $\mathrm{mm}$ is selected based on ISO 1997 standard. 
Table 1. Process parameters and various levels of experimentation.

\begin{tabular}{|l|c|c|c|c|c|}
\hline \multirow{2}{*}{$\begin{array}{l}\text { Process } \\
\text { Parameters }\end{array}$} & -2 & -1 & 0 & 1 & 2 \\
\hline $\begin{array}{l}\text { Rotational Speed } \\
\text { (rpm), } \mathrm{X}_{1}\end{array}$ & 50 & 75 & 100 & 125 & 150 \\
\hline $\begin{array}{l}\text { Working Gap } \\
\text { (mm), } \mathrm{X}_{2}\end{array}$ & 0.5 & 0.75 & 1 & 1.25 & 1.5 \\
\hline $\begin{array}{l}\text { Weight of } \\
\text { Abrasives } \\
\text { (gm), } \mathrm{X}_{3}\end{array}$ & 4 & 5 & 6 & 7 & 8 \\
\hline $\begin{array}{l}\text { Feed Rate } \\
(\mathrm{mm} / \mathrm{min}), \mathrm{X}_{4}\end{array}$ & 5 & 10 & 15 & 20 & 25 \\
\hline
\end{tabular}

The electronic weighing balance, make Contech (MODEL-CAH1003) having an accuracy of $0.001 \mathrm{mg}$ is used to measure the initial and final weights. The MRR is calculated by using the Equation 11.

$$
\operatorname{MRR}(\mathrm{mg} / \mathrm{min})=\frac{\text { Initial weight }- \text { Final weight }}{\text { Finishing time }}
$$

Design of experiments is a highly vital step in the utmost practical work. The purpose of experimentation is to build a relation between the responses and the process parameters. Central Composite Design (CCD) and Orthogonal arrays are the regularly applied techniques which have lesser number of experiments and gives outcomes with great accuracy. CCD will presume a second order behavior of the objective for a vast range of process parameters, whereas, orthogonal arrays will presume a first order behavior of the objective for a smaller range of process parameters. Therefore, the CCD technique has been preferred for the current work to get a second order model. Experiments were designed using response surface methodology with $2^{k}$ (where, $\mathrm{k}=$ number of variables; in this study, $\mathrm{k}=4$ ) factorial, central-composite second order ratable design. This consist of the number of corner points $=16$, a center point at zero level $=4$, and number of axial points $=8$. The axial points are located through parameter ' $\alpha$ ' in a coded test condition region. For ratable design, parameter ' $\alpha$ ' is calculated as $\left(2^{k}\right)^{1 / 4}=2$. To estimate the pure error, the center point is replicated four times. Equation 12 shows the conversion of the coded value corresponding to the actual value for every process variable. Equation 13 shows the response equation for central-composite second order ratable design.

$$
\begin{gathered}
\text { Coded test condition }=\frac{\text { actual test condition }- \text { mean test condition }}{(\text { range of test conditions }) / 2} \\
Y=b_{0}+\sum_{i=1}^{k} b_{i} x_{i}+\sum_{i=1}^{k} b_{i i} x_{i}^{2}+\sum_{j>1}^{k} b_{i j} x_{i} x_{j}
\end{gathered}
$$

where, $\mathrm{Y}$ is the response variable, $b_{i}, b_{i i}$ and $b_{i j}$ are constants and $k$ is the number of variables. $x_{i}, x_{i}^{2}$ and $x_{i} x_{j}$ represents the first order, second order and interaction terms of the process parameters respectively. Values of these constants are estimated by the least square method. To find the effect of process parameters on responses a polynomial response of second order is fitted using Equation 13. Using multiple regression technique, the mathematical models are derived for surface roughness $\left(R_{a}\right)$ as shown in Equation 14 and MRR as shown in Equation 15, by finding the coefficients $b_{i}, b_{i i}$ and $b_{i j}$.

$$
\begin{aligned}
& R_{a}=0.016083333+0.000569444 X_{1}+0.001208333 X_{2}-0.000375 X_{3} \\
&+ 0.00559722 X_{4}-0.00028125 X_{1}^{2}+0.001135417 X_{2}^{2}+0.002302083 X_{3}^{2} \\
&+0.00196875 X_{4}^{2}+0.000895833 X_{1} X_{2}-0.002229167 X_{1} X_{3} \\
&-0.0000208333 X_{1} X_{4}-0.0019375 X_{2} X_{3}-0.0015625 X_{2} X_{4} \\
&+0.0008125 X_{3} X_{4}
\end{aligned}
$$




$$
\begin{aligned}
M R R= & 0.005193306+0.000384671 X_{1}-0.000673095 X_{2}-0.000256429 X_{3} \\
& +0.001362179 X_{4}+0.0000599898 X_{1}^{2}+0.0000599898 X_{2}^{2} \\
& -0.0000842687 X_{3}^{2}-0.0000604799 X_{4}^{2}+0.000240385 X_{1} X_{2} \\
& +0.000769231 X_{1} X_{3}+0.000528846 X_{1} X_{4}+0.000625 X_{2} X_{3} \\
& -0.000192308 X_{2} X_{4}+0.000144231 X_{3} X_{4}
\end{aligned}
$$

Table 2. Details of experimentation and the results.

\begin{tabular}{|c|c|c|c|c|c|c|}
\hline $\begin{array}{c}\text { Ex. } \\
\text { No. }\end{array}$ & $\begin{array}{c}\text { Rotational Speed } \\
(\mathrm{rpm})\end{array}$ & $\begin{array}{c}\text { Working } \\
\text { Gap } \\
(\mathrm{mm})\end{array}$ & $\begin{array}{c}\text { Wt. of abrasive } \\
(\mathrm{gm})\end{array}$ & $\begin{array}{c}\text { Feed Rate } \\
(\mathrm{mm} / \mathrm{min})\end{array}$ & $\begin{array}{c}\text { Surface Roughness, } \\
(\mu \mathrm{m})\end{array}$ & $\begin{array}{c}\text { Material } \\
\text { Removal } \\
\text { Rate, } \\
(\mathrm{mg} / \mathrm{min})\end{array}$ \\
\hline 1 & 75 & 0.75 & 5 & 10 & 0.014 & 5.385 \\
\hline 2 & 125 & 0.75 & 5 & 10 & 0.012 & 3.846 \\
\hline 3 & 75 & 1.25 & 5 & 10 & 0.013 & 4.231 \\
\hline 4 & 125 & 1.25 & 5 & 10 & 0.016 & 2.308 \\
\hline 5 & 75 & 0.75 & 7 & 10 & 0.013 & 3.077 \\
\hline 6 & 125 & 0.75 & 7 & 10 & 0.014 & 4.615 \\
\hline 7 & 75 & 1.25 & 7 & 10 & 0.017 & 3.077 \\
\hline 8 & 125 & 1.25 & 7 & 10 & 0.020 & 1.923 \\
\hline 9 & 75 & 0.75 & 5 & 20 & 0.017 & 9.231 \\
\hline 10 & 125 & 0.75 & 5 & 20 & 0.023 & 8.462 \\
\hline 11 & 75 & 1.25 & 5 & 20 & 0.019 & 4.615 \\
\hline 12 & 125 & 1.25 & 5 & 20 & 0.034 & 3.846 \\
\hline 13 & 75 & 0.75 & 7 & 20 & 0.039 & 6.154 \\
\hline 14 & 125 & 0.75 & 7 & 20 & 0.032 & 6.154 \\
\hline 15 & 75 & 1.25 & 7 & 20 & 0.027 & 3.077 \\
\hline 16 & 125 & 1.25 & 7 & 20 & 0.018 & 10.000 \\
\hline 17 & 100 & 1 & 6 & 15 & 0.017 & 4.616 \\
\hline 18 & 100 & 1 & 6 & 15 & 0.015 & 5.770 \\
\hline 19 & 100 & 1 & 6 & 15 & 0.017 & 5.193 \\
\hline 20 & 100 & 1 & 6 & 15 & 0.014 & 5.193 \\
\hline 21 & 150 & 1 & 6 & 15 & 0.017 & 7.501 \\
\hline 22 & 50 & 1 & 6 & 15 & 0.015 & 4.039 \\
\hline 23 & 100 & 1.5 & 6 & 15 & 0.029 & 5.193 \\
\hline 24 & 100 & 0.5 & 6 & 15 & 0.015 & 6.347 \\
\hline 25 & 100 & 1 & 8 & 15 & 0.016 & 4.616 \\
\hline 26 & 100 & 1 & 4 & 15 & 0.037 & 5.770 \\
\hline 27 & 100 & 1 & 6 & 25 & 0.036 & 7.692 \\
\hline 28 & 100 & 1 & 6 & 5 & 0.014 & 2.885 \\
\hline & & & & & & \\
\hline & & 5 & 6 & 5 & & \\
\hline
\end{tabular}

Table 3. Set of Pareto optimal solution using MO-ABC algorithm.

\begin{tabular}{|c|c|c|c|c|c|c|}
\hline $\begin{array}{c}\text { Sol. } \\
\text { No. }\end{array}$ & $\begin{array}{c}\text { Rotational } \\
\text { Speed } \\
(\mathrm{rpm})\end{array}$ & $\begin{array}{c}\text { Working } \\
\text { Gap }(\mathrm{mm})\end{array}$ & $\begin{array}{c}\text { Wt. of } \\
\text { abrasive } \\
(\mathrm{gm})\end{array}$ & $\begin{array}{c}\text { Feed Rate } \\
(\mathrm{mm} / \mathrm{min})\end{array}$ & $\begin{array}{c}\text { Surface } \\
\text { Roughness, } \\
(\mu \mathrm{m})\end{array}$ & $\begin{array}{c}\text { Material } \\
\text { Removal Rate, } \\
(\mathrm{mg} / \mathrm{min})\end{array}$ \\
\hline $1^{*}$ & 150 & 0.5 & 7 & 5 & 0.004 & 0.823 \\
\hline 2 & 50 & 0.6 & 5 & 6 & 0.006 & 1.475 \\
\hline $3^{*}$ & 139 & 0.60 & 6 & 7 & 0.007 & 2.503 \\
\hline 4 & 50 & 0.84 & 5 & 11 & 0.008 & 3.893 \\
\hline 5 & 62 & 0.75 & 5 & 7 & 0.008 & 2.950 \\
\hline 6 & 150 & 0.89 & 8 & 6 & 0.008 & 2.990 \\
\hline 7 & 150 & 0.77 & 8 & 5 & 0.008 & 2.654 \\
\hline
\end{tabular}




\begin{tabular}{|c|c|c|c|c|c|c|}
\hline 8 & 150 & 0.96 & 7 & 11 & 0.010 & 4.039 \\
\hline 9 & 107 & 0.78 & 6 & 8 & 0.011 & 5.689 \\
\hline 10 & 150 & 1.04 & 8 & 12 & 0.011 & 4.698 \\
\hline 11 & 150 & 1.16 & 8 & 11 & 0.011 & 4.125 \\
\hline 12 & 71 & 1.0 & 6 & 11 & 0.012 & 6.622 \\
\hline 13 & 150 & 1.13 & 7 & 12 & 0.012 & 6.570 \\
\hline 14 & 117 & 0.97 & 7 & 8 & 0.012 & 6.440 \\
\hline 15 & 96 & 0.97 & 6 & 10 & 0.012 & 5.970 \\
\hline 16 & 50 & 1.11 & 4 & 10 & 0.013 & 6.650 \\
\hline 17 & 64 & 1.08 & 6 & 14 & 0.014 & 6.792 \\
\hline 18 & 131 & 1.06 & 7 & 15 & 0.015 & 7.277 \\
\hline 19 & 50 & 1.39 & 7 & 16 & 0.018 & 7.484 \\
\hline $20 *$ & 131 & 0.96 & 7 & 18 & 0.020 & 8.855 \\
\hline
\end{tabular}

* - experiments for validation

The experimentation matrix and the corresponding values of MRR and surface roughness are shown in Table 2.

The multi-objective optimization model formulated for the two conflicting objectives as,

Objective 1: Minimization of surface roughness is given in Equation 14.

Objective 2: Maximization of material removal rate is given in Equation 15.

The Pareto optimal solutions obtained by MO-ABC algorithm are shown in Table 3 and the Pareto front is plotted in Figure 6. Pareto front for two objective functions shows that as the MRR decreases, the surface roughness will also decrease. For non-dominated solutions obtained by MO-ABC algorithm, Figure 7 shows the graph of combined objective function versus iteration number, the final combined objective function value $(Z)$ is 1.218 and it is 2.264 , for the initial data set obtained experimentally.

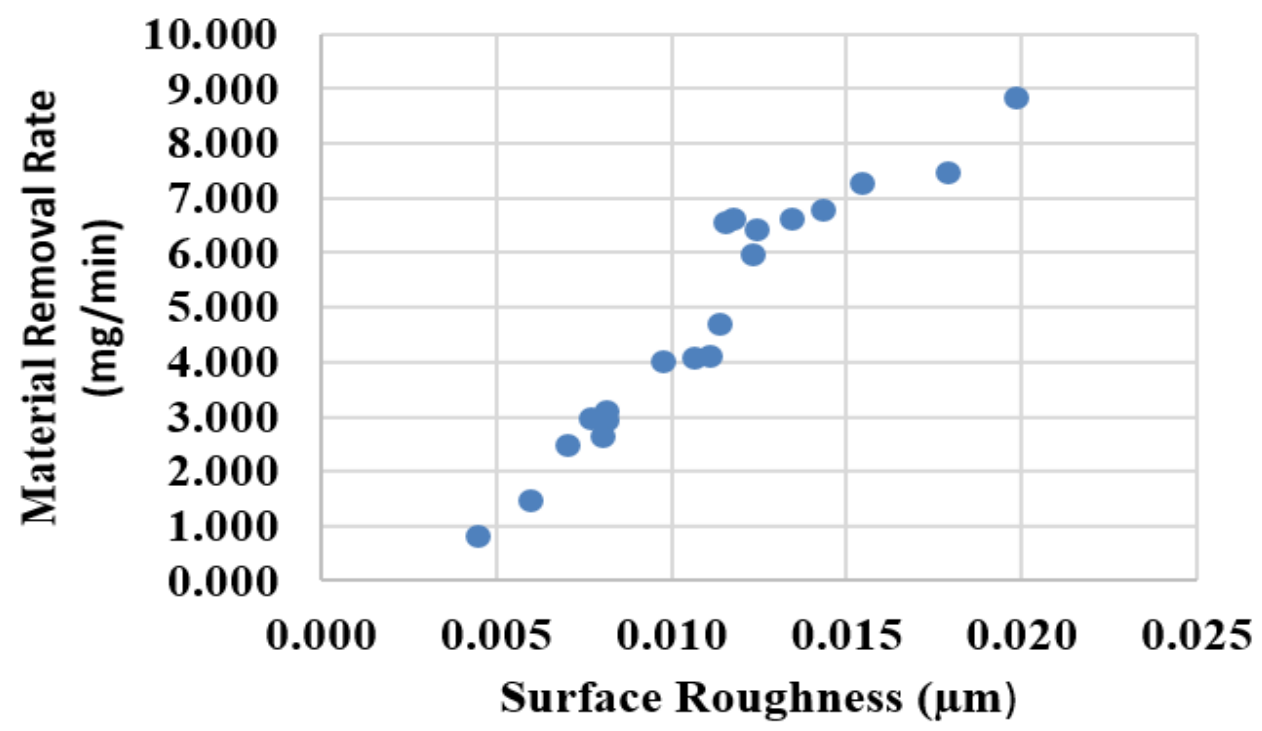

Figure 6. Pareto front for two objective functions.

Figure 8 shows the value path plot for the choice of process variables to get the best output of both responses, it is drawn from the set of 20 Pareto-optimal solutions. The value of the rotational speed of the tool $\left(X_{1}\right)$ seems to be spread uniformly over the entire range (i.e. from 50-150 rpm), for working gap $\left(X_{2}\right)$ it is between $0.5-1.39 \mathrm{~mm}$, for weight of abrasive $\left(X_{3}\right)$ it is between 4.2-8 gm and for feed rate $\left(X_{4}\right)$ it is between $5-18 \mathrm{~mm} / \mathrm{min}$. The graph is plotted for understanding the effect of process variables on surface roughness as shown in Figure 9. The effect of rotational speed is plotted by considering its different values and keeping the 
other parameters at their optimum level for the minimum surface roughness (i.e. solution number 1 in table 3 ). Similarly, the effect of other process parameters is plotted. For higher rotational speed of the tool, the surface finish increases as it enhances the reaction force on flexible magnetic abrasive brush chains due to increased collision among these chains and workpiece surface. In addition, at higher rotational speed of tool the centripetal force required to hold the flexible magnetic abrasive brush increases. These results in cutting of peaks of the workpiece surface in different directions resulting in higher surface finish. It is observed from graph that, initially the surface finish is lower for the working gap of $0.5 \mathrm{~mm}$, this could be due to decrease in total number of abrasives and then surface finish value increases for the working gap up to $1 \mathrm{~mm}$ due to higher magnetic flux density available to hold the magnetic abrasive particles. Further increase in working gap decreases the surface finish, this may be due to lower magnetic flux density. The surface finish decreases with increase in weight of abrasive as the number of cutting edges of the abrasives particles are greater which results in increased collisions. It can be seen that for the lower feed rate values the surface finish is better, this is because the flexible magnetic abrasive brush travels slowly with respect to the workpiece at lower feed rate, thus the more number of impacts will occur with the peaks of the surface texture.

From Table 3, few solutions (solution no. 1, 3 and 20) are validated experimentally and the validation results are shown in Table 4. Average deviations between predicted and experimental values of MRR and surface roughness are $0.450 \mathrm{mg} / \mathrm{min}$ and $0.001 \mu \mathrm{m}$ respectively. To demonstrate the mirror finish produced on the workpiece (for solution No. 1), the image of letters ABCDEFG is taken on the workpiece as shown in Figure 11, which clearly reveals the level of surface finish achieved.

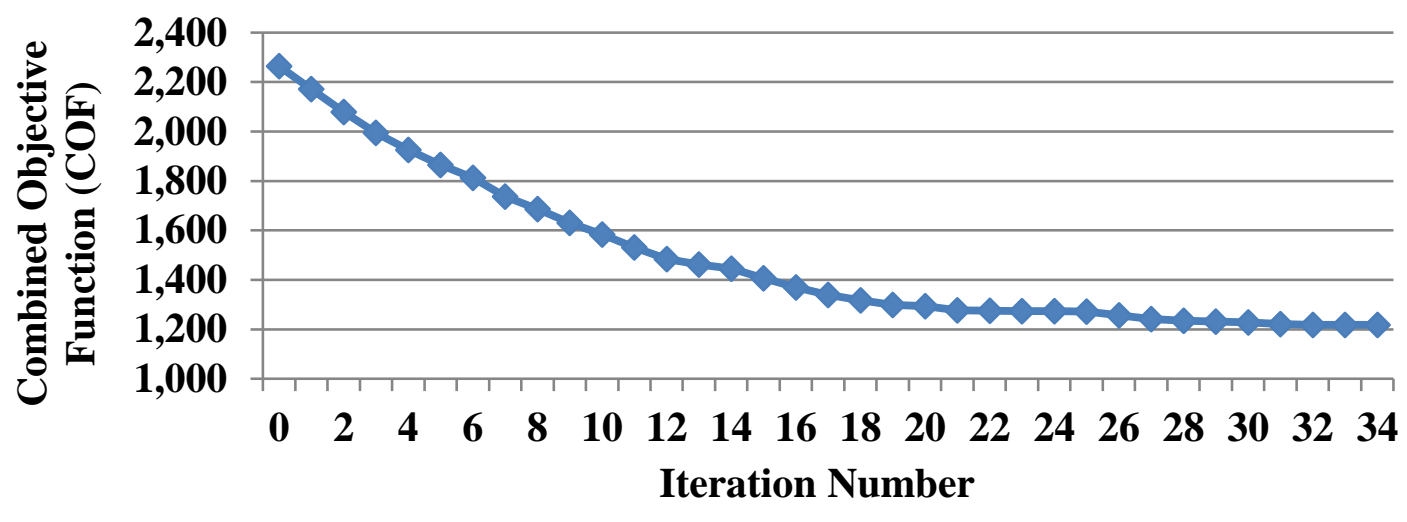

Figure 7. Combined objective function versus iteration number for non-dominated solutions of MO-ABC algorithm.

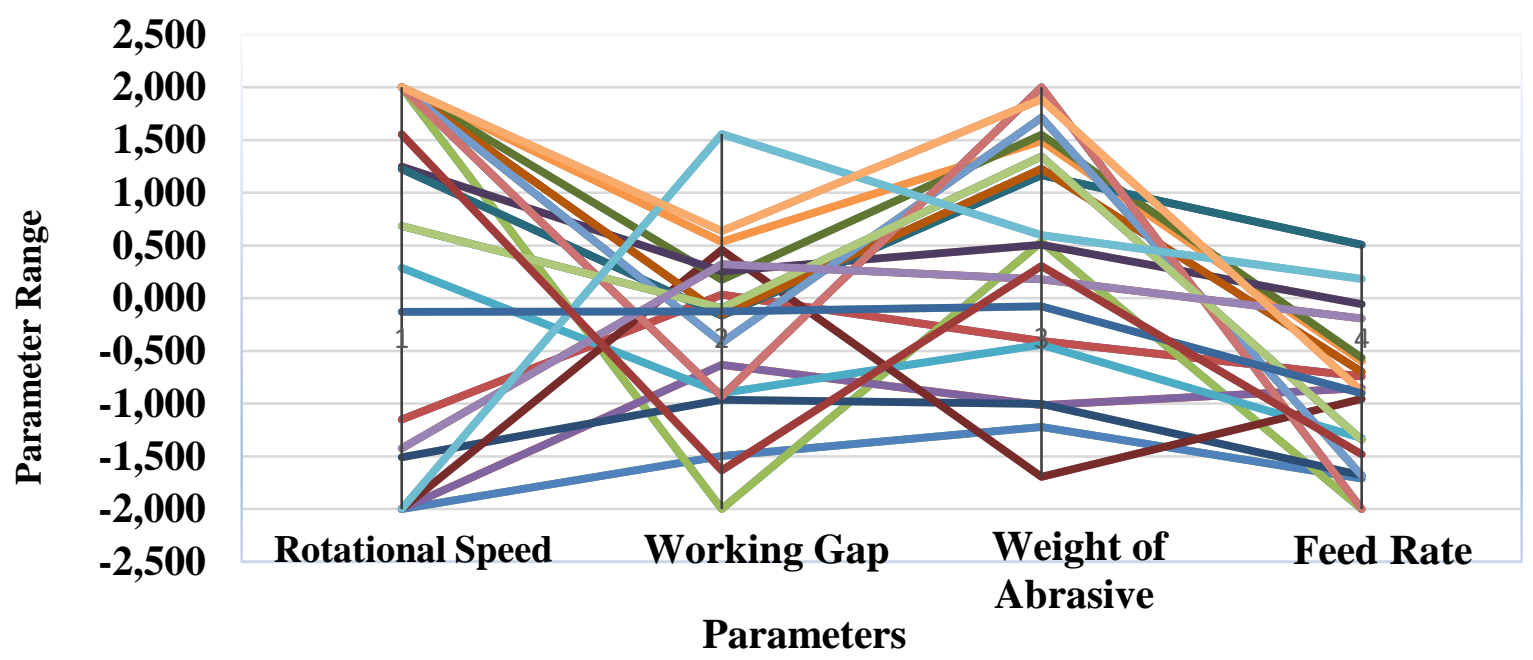

Figure 8. Value path plot. 


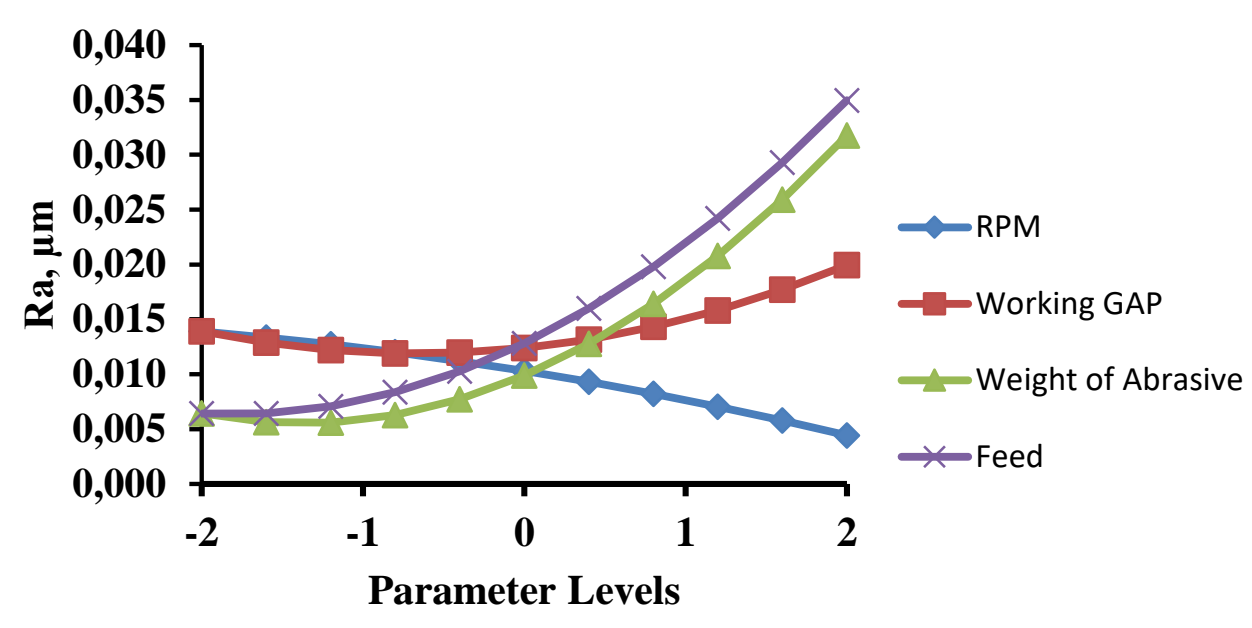

Figure 9. Effect of process variables on surface roughness.

Table 4. Experimental validations of MO-ABC algorithm optimal solutions.

\begin{tabular}{|c|c|c|c|c|c|c|}
\hline \multirow{2}{*}{$\begin{array}{c}\text { Sol. } \\
\text { No. }\end{array}$} & \multicolumn{2}{|c|}{ Surface Roughness $\left(R_{a}\right), \mu \mathrm{m}$} & \multicolumn{3}{|c|}{ Material Removal Rate, $\mathrm{mg} / \mathrm{min}$} \\
\cline { 2 - 7 } & Pred. & Expt. & $\begin{array}{c}\delta \\
(\mu \mathrm{m})\end{array}$ & Pred. & Expt. & $\begin{array}{c}\delta \\
(\mathrm{mg} / \mathrm{min})\end{array}$ \\
\hline 1 & 0.004 & 0.005 & 0.001 & 0.823 & 0.842 & 0.019 \\
\hline 3 & 0.007 & 0.006 & 0.001 & 2.503 & 2.652 & 0.149 \\
\hline 20 & 0.020 & 0.022 & 0.002 & 8.855 & 7.671 & 1.184 \\
\hline
\end{tabular}

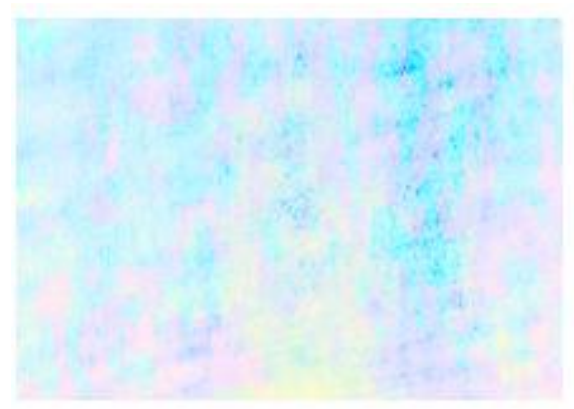

(a)

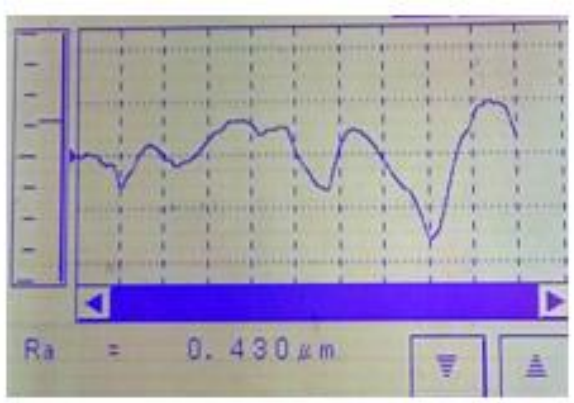

(b)

Figure 10. (a) Photograph of the specimen before finishing (b) Surface roughness profile before finishing $\left(R_{a}=0.430 \mu \mathrm{m}\right)$.

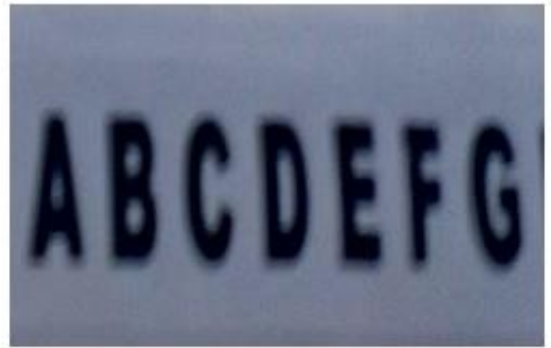

(a)

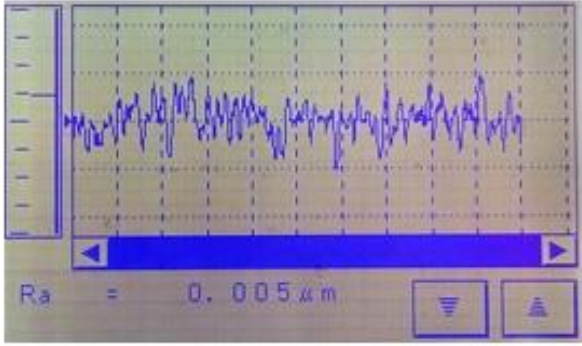

(b)

Figure 11. (a) Photograph of the specimen after finishing, experimental conditions: rotational speed = 150; working gap $=0.5 \mathrm{~mm}$; weight of abrasive $=6.53 \mathrm{gm}$; feed rate $=5 \mathrm{~mm} / \mathrm{min}(\mathrm{b})$ Surface roughness profile after finishing $\left(R_{a}=0.005 \mu \mathrm{m}\right)$. 


\section{Conclusions}

1. By using MO-ABC algorithm a set of 20 non-dominated solutions are obtained, it may be used as a ready reference to process planner for setting the parameters on the machine as per requirement.

2. As shown in Table 3, the best possible value of surface roughness is $0.004 \mu \mathrm{m}$ (with material removal rate of $0.823 \mathrm{mg} / \mathrm{min}$.) and the best possible value of MRR is $8.855 \mathrm{mg} / \mathrm{min}$ (with surface roughness of 0.020 $\mu \mathrm{m})$.

3. The value path plot shows the following range process parameters for the MAF process to offer the best process performance with respect to both objectives.

a. Rotational speed of the tool $\left(X_{1}\right)$ : Complete range $(50-150 \mathrm{rpm})$

b. Working gap $\left(X_{2}\right)$ : Lower to middle range $(0.5-1.39 \mathrm{~mm})$

c. Weight of abrasive $\left(X_{3}\right)$ : Almost complete range (4.2-8 gm)

d. Feed rate $\left(X_{4}\right)$ : Lower to middle range $(5-18 \mathrm{~mm} / \mathrm{min})$

4. For non-dominated solutions obtained by using MO-ABC algorithm, the final combined objective function value $(Z)$ is 1.218 and it is 2.264 for initial data set obtained experimentally, thus the overall improvement of $46.20 \%$ is achieved.

5. The results are experimentally validated and it shows that the average absolute deviation of $0.450 \mathrm{mg} / \mathrm{min}$ and $0.001 \mu \mathrm{m}$ for MRR and surface roughness respectively.

\section{References}

[1] Judal, K. B., Yadava V.: Cylindrical electrochemical magnetic abrasive machining of AISI-304 stainless steel. Materials and Manufacturing Processes, 28 (2013), 449-456.

[2] Judal, K. B., Yadava, V., Pathak, D.: Experimental investigation of vibration assisted cylindrical magnetic abrasive finishing of aluminum workpiece. Materials and Manufacturing Processes, 28 (2013), 1196-1202.

[3] Mulik, R. S., Pandey, P. M.: Ultrasonic assisted magnetic abrasive finishing of hardened AISI 52100 steel using unbondedSiC abrasives. Int. Journal of Refractory Metals and Hard Materials, 29 (2011), 68-77.

[4] Kumar, S., Jain, V. K., Sidpara, A.: Nano finishing of freeform surfaces (Knee joint implant) by Rotational-magneto rheological abrasive flow finishing ( $R$-MRAFF) process. Precision Engineering, 42 (2015), 165-178.

[5] Dewangan, A. K., Patel, A. D., Bhadania, A. G.: Stainless Steel for Dairy and Food Industry: A Review. Journal of Material Sciences and Engineering, 4 (2015), 5.

[6] Kaladhar, M., Subbaiah, K. V., Rao, C., H. S.: Machining of austenitic stainless steels - a review: Int. J. Machining and Machinability of Materials, 12 (2012), 178-192.

[7] Yang, L., Lin, C., Chow, H.: Optimization in MAF operations using Taguchi parameter design for AISI304 stainless steel.Int J AdvManufTechnol, 42 (2009), 595-605.

[8] Heng, L. K., Yon, J., Mun, S. D.: Review of super finishing by the magnetic abrasive finishing process. High Speed Mach, 3 (2017), 42-55.

[9] Hsinn-Jyh, T., Biing-Hwa, Y., Rong-Tzong, H., Han-Ming C.: Finishing effect of abrasive flow machining on micro slit fabricated by wire-EDM. Int J AdvManufTechnol, 34 (2007), 649-656.

[10] Deng, T., Zheng, Z., Li, J., Xiong Y., Li, J.: Surface polishing of AISI 304 stainless steel with micro plasma beam irradiation. Applied Surface Science, 476 (2019), 796-805.

[11] Okada, A., Uno, Y., McGeough, J. A., Fujiwara, K., Doi, K., Uemura K., Sano, S.: Surface finishing of stainless steels for orthopedic surgical tools by large-area electron beam irradiation. CIRP Annals - Manufacturing Technology, 57 (2008), 223-226.

[12] Kwak, J.: Mathematical model determination for improvement of surface roughness in magneticassisted abrasive polishing of nonferrous AISI316 material. Trans. Nonferrous Met. Soc. China, 22 (2012), 845-850.

[13] Kala, P., Pandey P. M.: Comparison of finishing characteristics of two paramagnetic materials using double disc magnetic abrasive finishing. Journal of Manufacturing Processes, 17 (2015), 63-77.

[14] Lin, C., Yang, L., Chow, H.: Study of magnetic abrasive finishing in free-form surface operations using the Taguchi method.Int J Adv Manuf Technol, 34 (2007), 122-130. 
[15] Girma, B., Joshi, S. S., Raghuram, M. V., G. S., Balasubramaniam, R.: An experimental analysis of magnetic abrasives finishing of plane surfaces. Machining Science and Technology, 10 (2006), 323340.

[16] Wang Y., Hu D.: Study on the inner surface finishing of tubing by magnetic abrasive finishing. International Journal of Machine Tools and Manufacture, 45 (2005), 43-49.

[17] Sadiq, A., Shunmugam, M. S.: Magnetic field analysis and roughness prediction in magnetorheological abrasive honing. Machining Science and Technology, 13 (2009), 246-268.

[18] Sadiq, A., Shunmugam, M. S.: A novel method to improve finish on non-magnetic surfaces in magneto- rheological abrasive honing process. Tribology International, 43 (2010), 1122-1126.

[19] Jang K., Kim, D., Maeng S., Lee, W., Han, J., Seok, J., Je, T., Kang, S., Min, B.: Deburring micro parts using a magneto rheological fluid. International Journal of Machine Tools and Manufacture, 53 (2012), 170-175.

[20] Das, M., Jain, V. K., Ghoshdastidar, P. S.: Analysis of magneto-rheological abrasive flow finishing (MRAFF) process. Int J Adv Manuf Technol, 38 (2008), 613-621.

[21] Das, M., Jain, V. K., Ghoshdastidar, P. S.: Nano-finishing of stainless-steel tubes using rotational magneto-rheological abrasive flow Finishing process. Machining Science and Technology, 14 (2010), 365-389.

[22] Das, M., Jain, V. K., Ghoshdastidar, P. S.: The Out-of-Roundness of the Internal Surfaces of Stainless Steel Tubes Finished by the Rotational-Magneto-rheological Abrasive Flow Finishing Process. Materials and Manufacturing Processes, 26 (2011), 1073-1084.

[23] Das, M., Jain, V. K., Ghoshdastidar, P. S.: Nano finishing of flat workpieces using rotationalmagnetorheological abrasive flow finishing $(R-M R A F F)$ process. Int J Adv Manuf Technol, 62 (2012), 405-420.

[24] Jha, S., Jain, V. K., Komanduri R.: Effect of extrusion pressure and number of finishing cycles on surface roughness in magneto-rheological abrasive flow finishing (MRAFF) process. Int $\mathrm{J}$ Adv Manuf Technol, 33 (2007), 725-729.

[25] Chaurasia, A., Rattan, N., Mulik, R. S.: Magnetic abrasive finishing of AZ91 magnesium alloy using electromagnet. Journal of the Brazilian Society of Mechanical Sciences and Engineering. 40 (2018).

[26] Kwak, J.: Enhanced magnetic abrasive polishing of non-ferrous metals utilizing a permanent magnet. International Journal of Machine Tools \& Manufacture, 49 (2009), 613-618.

[27] Kim, S. O., Kwak, J. S.: Magnetic force improvement and parameter optimization for magnetic abrasive polishing of AZ31 magnesium alloy. Trans. Nonferrous Met. Soc. China, 18 (2008), s369s373.

[28] Kim, T., Kang, D., Kwak, J.: Application of magnetic abrasive polishing to composite materials. Journal of Mechanical Science and Technology, 24 (2010), 5, 1029-1034.

[29] Muhamad, M. R., Zou, Y., Sugiyama H.: Investigation of the finishing characteristics in an internal tube finishing process by magnetic abrasive finishing combined with electrolysis. The International Journal of Surface Engineering and Coatings, 94 (2016), 3, 159-165.

[30] Nepomnyashchii, V. V., Voloshchenko, S. M., Mosina, T. V., Gogaev, K. A., Askerov, M. G., Miropol'skii, A. M.: Metal surface finishing with magnetic abrasive powder based on iron with ceramic refractory compounds (mechanical mixtures). Refractories and Industrial Ceramics, 54 (2014), 6, 471-474.

[31] Zhou, K., Chen, Y., Du, Z. W., Niu, F. L.: Surface integrity of titanium part by ultrasonic magnetic abrasive finishing. The International Journal of Advanced Manufacturing Technology, 80 (2015), 5-8, 997-1005.

[32] Kwak, J.: Mathematical model determination for improvement of surface roughness in magneticassisted abrasive polishing of nonferrous AISI316 material. Trans. Nonferrous Met. Soc. China, 22 (2012), s845-s850.

[33] Pa, P.S.: The optimal parameters in a magnetically assisted finishing system using Taguchi's method. Physica, B 405 (2010), 4470-4475.

[34] Kala, P., Kumar, S., Pandey, P. M.: Polishing of Copper Alloy Using Double Disk Ultrasonic Assisted Magnetic Abrasive Polishing. Materials and Manufacturing Processes, 28 (2013), 200-206.

[35] Singh, D. K., Jain, V. K., Raghuram, V.: Parametric study of magnetic abrasive finishing process. Journal of Materials Processing Technology, 149 (2004), 22-29. 
[36] Yan, B., Chang, G., Chang, J., Hsu, R.: Improving Electrical Discharge Machined Surfaces Using Magnetic Abrasive Finishing. Machining Science and Technology, 8 (2004), 1, 103-118.

[37] Wang, A., Tsai, L., Liu, C. H., Liang, K. Z., Lee, S. J.: Elucidating the Optimal Parameters in Magnetic Finishing with Gel Abrasive. Materials and Manufacturing Processes, 26 (2011), 786-791.

[38] Singh, D. K., Jain, V. K., Raghuram, V.: Experimental investigations into forces acting during a magnetic abrasive finishing process. Int J Adv Manuf Technol, 30 (2006), 652-662.

[39] Mulik, R.S., Pandey, P. M.: Mechanism of surface finishing in ultrasonic assisted magnetic abrasive finishing process. Materials and Manufacturing Processes, 25 (2010), 1418-1427.

[40] Nguyen, N., Yin, S., Chen, F., Yin, H., Pham, V., Tran, T.: Multi-objective optimization of circular magnetic abrasive polishing of SUS304 and Cu materials. Journal of Mechanical Science and Technology, 30 (2016), 6, 2643-2650.

[41] Nguyen, N., Tran, T., Yin, S., Chau, M., Le, D.: Multi-objective optimization of improved magnetic abrasive finishing of multi-curved surfaces made of SUS202 material. Int J Adv Manuf Technol, 88 (2017), 1-4, 381-391.

[42] Misra, A., Pandey, P. M., Dixit, U. S., Roy A., Silberschmidt, V. V.: Multi-objective optimization of ultrasonic-assisted magnetic abrasive finishing process. The International Journal of Advanced Manufacturing Technology, 101 (2018) 5-8, 1661-1670.

[43] Pawar, P. J., Vidhate, U. S., Khalkar, M. Y.: Improving the quality characteristics of abrasive water jet machining of marble material using multi-objective artificial bee colony algorithm. Journal of Computational Design and Engineering, 5 (2018), 3, 319-328.

[44] Mulik, R. S., Pandey, P. M.: Magnetic abrasive finishing of hardened AISI 52100 steel. Int J Adv Manuf Technol, 55 (2011), 501-515.

[45] Jain V. K., Kumar, B. P., Jayswal S.: Effect of working gap and circumferential speed on the performance of magnetic abrasive finishing process. Wear, 250 (2001), 384-90. 